\title{
La obtención coactiva de la muestra genética para la investigación criminal en España*
}

\section{Ignacio eAcón Ortego*}

Para citar este artículo

Acón, I. (2020). La obtención coactiva de la muestra genética para la investigación criminal en España. Revista Via luris, 29, 185-204. DOI: https://doi. org/10.37511/viaiuris.n29a7.

\section{RESUMEN}

La obtención de las muestras biológicas para su posterior análisis sigue siendo la principal fuente de problemas de la prueba de ADN. En España, la reforma llevada a cabo en el año 2015 introdujo la posibilidad de la obtención coactiva de la muestra, previa la oportuna autorización judicial, lo que añade una nueva dimensión a la problemática que es preciso analizar viendo cómo se está llevando a cabo en nuestros tribunales. Se trata de comprender el fundamento de esta decisión legislativa y su adecuación al orden constitucional y al respeto de los derechos fundamentales, así como examinar los problemas que pueden derivarse de su aplicación: en qué supuestos es aplicable; bajo qué condiciones; cómo tiene que ser la resolución judicial habilitante; qué debemos entender por "medidas coactivas mínimas indispensables, proporcionadas a las circunstancias del caso y respetuosas con su dignidad"; cómo debe llevarse a cabo, en definitiva, una diligencia tan problemática como es la ejecución coactiva del análisis del ADN.

* Artículo de reflexión como resultado del trabajo de investigación para la elaboración de tesis doctoral sobre "Aspectos procesales del uso del ADN en investigación criminal", en el Programa de Doctorado en Unión Europea de la UNED, Madrid (España), (Periodo 2019-2023).

** Candidato a Doctor en Unión Europea - UNED. Magíster en Derechos Fundamentales por la UNED. Licenciado en Derecho por la Universidad de Zaragoza (España). Vocal titular de la Comisión Nacional para el Uso Forense del ADN (CNUFADN) y vocal coordinador del Grupo Jurídico y Bioético de la Comisión, durante los años 2012 a 2017. En la actualidad, Juez-Magistrado titular del Juzgado de Primera Instancia e Instrucción no. 2 de Calahorra (La Rioja). Zaragoza (España). Correo electrónico de contacto: i.acon@ poderjudicial.es. ORCID: https:// orcid.org/0000-0002-9920-3275.
DOI: https://doi.org/10.37511/viaiuris.n29a7

Licencia Creative Commons

Esta obra está bajo una Licencia Creative Commons Atribución-NoComercial-Compartirlgual 2.5 Colombia.

\section{(c) (1)(2)}

\section{Palabras clave}

ADN; muestras genéticas; análisis de ADN; uso de la fuerza; investigación criminal; garantías procesales. 


\title{
The coercive obtain of the genetic sample for criminal investigation in Spain
}

\author{
Ignacio Acón Ortego
}

\begin{abstract}
Obtaining biological samples for subsequent analysis continues to be the main source of problems with DNA testing. In Spain, the reform carried out in 2015 introduced the possibility of coercive obtaining of the sample, subject to the appropriate judicial authorization, which adds a new dimension to the problem that needs to be analyzed by seeing how it is being carried out in our courts. The aim is to understand the basis of this legislative decision and its adequacy to the constitutional order and respect for fundamental rights, as well as to examine the problems that may arise from its application: in which cases it is applicable; under what conditions; how the enabling judicial resolution has to be; what we should understand by "indispensable minimum coercive measures, proportionate to the circumstances of the case and respectful of his dignity"; how should be carried out, in short, such a problematic diligence as is the coercive execution of DNA analysis.
\end{abstract}

\section{Keywords}

DNA; genetic samples; DNA analysis; use of force; criminal investigation; procedural guarantees. 


\title{
A recolha coerciva de amostras genéticas para investigação criminal em Espanha
}

\author{
Ignacio Acón Ortego
}

\section{RESUMO}

A obtenção de amostras biológicas para análise posterior continua a ser a principal fonte de problemas nos testes de ADN. Em Espanha, a reforma levada a cabo em 2015 introduziu a possibilidade de recolha coerciva da amostra, sujeita à devida autorização judicial, o que acrescenta uma nova dimensão ao problema que precisa de ser analisado, analisando a forma como está a ser levada a cabo nos nossos tribunais. O objectivo é compreender a base desta decisão legislativa e a sua adaptação à ordem constitucional e ao respeito pelos direitos fundamentais, bem como examinar os problemas que podem surgir da sua aplicação: em que casos é aplicável; em que condições; como deve ser a decisão judicial de habilitação; o que devemos entender por "medidas coercivas mínimas indispensáveis, proporcionais às circunstâncias do caso e respeitadoras da sua dignidade"; como um procedimento tão problemático como a execução coerciva da análise de ADN deve ser levado a cabo, em suma, como deve ser levado a cabo.

Palavras-chave

ADN; amostras genéticas; análise de ADN; uso de força; investigação criminal; processo devido. 


\title{
La collecte efficace d'échantillons d'adn pour les enquêtes criminelles en Espagne
}

\author{
Ignacio Acón Ortego
}

\section{RÉSUMÉ}

L'obtention d'échantillons biologiques en vue d'une analyse ultérieure reste la principale source de problèmes dans les tests ADN. En Espagne, la réforme réalisée en 2015 a introduit la possibilité d'une collecte coercitive de l'échantillon, sous réserve de l'autorisation judiciaire appropriée, ce qui ajoute une nouvelle dimension au problème qu'il convient d'analyser en examinant comment elle est réalisée dans nos tribunaux. Il s'agit de comprendre les fondements de cette décision législative et son adaptation à l'ordre constitutionnel et au respect des droits fondamentaux, ainsi que d'examiner les problèmes que peut poser son application : dans quels cas elle est applicable ; à quelles conditions ; comment doit être la décision judiciaire d'habilitation ; ce qu'il faut entendre par " mesures coercitives minimales indispensables, proportionnées aux circonstances de l'espèce et respectueuses de leur dignité "; comment doit se dérouler une procédure aussi problématique que l'exécution coercitive d'une analyse ADN, en somme, comment elle doit être réalisée.

Mots-clés

ADN; échantillons génétiques; analyse ADN; recours à la force; enquête criminelle; procédure régulière. 


\section{INTRODUCCIÓN}

El enunciado de este trabajo puede resultar llamativo. Y es que ¿̇abe la obtención coactiva, mediante el uso de la fuerza, de muestras biológicas pertenecientes a un sujeto sometido a una investigación criminal? Cualquier jurista que haya estudiado mínimamente el tema de las intervenciones corporales desde el punto de vista de los derechos fundamentales responderá rápidamente que no. Todo lo más, cabe plantearse qué consecuencias pueden derivarse de la negativa del investigado a someterse a la prueba de ADN, pero no es posible su ejecución coactiva a riesgo de lesionar los derechos fundamentales más esenciales.

Pues bien, en España este planteamiento era así hasta que el legislador del año 2015 introdujo la posibilidad de obtener muestras biológicas del detenido mediante el empleo de medios coactivos. Hasta ese momento, la jurisprudencia y la doctrina mayoritaria venían entendiendo que si el sujeto sometido a investigación se negaba a entregar una muestra biológica, no era posible recurrir al uso de la fuerza para obtener una muestra con la que realizar el necesario informe comparativo del ADN.

En concreto, fue la Ley Orgánica 13/2015, de 5 de octubre, de modificación de la Ley de enjuiciamiento criminal para el fortalecimiento de las garantías procesales y la regulación de las medidas de investigación tecnológica, la que introdujo un nuevo artículo $(520.6$, c.) que establece lo siguiente:

6. La asistencia del abogado consistirá en:

(...) c) Informar al detenido de las consecuencias de la prestación o denegación de consentimiento a la práctica de diligencias que se le soliciten.

Si el detenido se opusiera a la recogida de las muestras mediante frotis bucal, conforme a las previsiones de la Ley Orgánica 10/2007, de 8 de octubre, reguladora de la base de datos policial sobre identificadores obtenidos a partir del ADN, el juez de instrucción, a instancia de la Policía Judicial o del Ministerio Fiscal, podrá imponer la ejecución forzosa de tal diligencia mediante el recurso a las medidas coactivas mínimas indispensables, que deberán ser proporcionadas a las circunstancias del caso y respetuosas con su dignidad. (Ley de Enjuiciamiento Criminal, 1882, artículo 520.6 c.)
En el presente trabajo nos proponemos analizar el fundamento de esta decisión legislativa y su adecuación al orden constitucional y al respeto de los derechos fundamentales, así como examinar los problemas que pueden derivarse de su aplicación, todo ello con el fin de extraer algunas conclusiones prácticas.

\section{METODOLOGÍA}

Todo estudio sobre el uso forense del ADN exige partir de unos postulados mínimos sobre el marco garantista y sus implicaciones en una triple vertiente: científica, jurídica y bioética. Teniendo en cuenta este marco general de actuación, comenzaremos con un planteamiento general sobre la toma de muestras de ADN para su utilización en investigación criminal.

Seguidamente, analizaremos las consecuencias jurídicas que pueden derivarse de la negativa del sujeto a la toma de muestras biológicas. Antes de la reforma del año 2015, la jurisprudencia del Tribunal Supremo español vedaba la posibilidad de acudir a medios coactivos para la obtención de muestras de ADN, si bien veremos que las objeciones jurisprudenciales al uso de la fuerza para la toma de muestras parecían referirse a la ausencia de norma legal habilitante, y no tanto a una posible inconstitucionalidad de la medida. Por ello no faltaban autores que, frente a la doctrina mayoritaria, sugerían la posibilidad de que el legislador, como ha terminado haciendo, pudiera legitimar determinados actos de compulsa física para proceder a la toma de muestras.

Llegaremos así a la reforma operada por la Ley Orgánica 13/2015, de 5 de octubre, y el nuevo artículo 520.6 c) de la Ley de Enjuiciamiento Criminal. Analizaremos el fundamento de esta modificación legislativa, para después entrar de lleno en los problemas que plantea su aplicación.

Nos proponemos un estudio de la problemática con un enfoque eminentemente práctico, alejado de postulados doctrinales o excesivamente teóricos. Para ello veremos el contenido de resoluciones judiciales que se han venido dictando en España para tratar de encauzar la nueva previsión normativa, previsión que también debe ponerse en relación con la misma regulación que introdujo nuestro legislador apenas unos meses antes, respecto de los perfiles de ADN de condenados (el artículo 129 bis del Código Penal). 
Todo ello nos permitirá, finalmente, extraer algunas conclusiones también prácticas sobre nuestro objeto de estudio: en qué supuestos es aplicable; bajo qué condiciones; cómo tiene que ser la resolución judicial habilitante; qué debemos entender por "medidas coactivas mínimas indispensables, proporcionadas a las circunstancias del caso y respetuosas con su dignidad" (Ley de Enjuiciamiento Criminal, 1882, artículo 520.6 c.); cómo debe llevarse a cabo, en definitiva, una diligencia tan problemática como la obtención coactiva de muestras biológicas para su análisis del ADN.

\section{RESULTADOS Y DISCUSIÓN}

\section{La obtención coactiva de la muestra genética en investigación criminal}

\section{La toma de muestras de ADN. Supuestos diferenciados}

La obtención de las muestras biológicas para su posterior análisis sigue siendo la principal fuente de problemas de la prueba de ADN. La ausencia o falta de claridad normativa provoca continuas dudas sobre la forma de actuar en cada caso, dando lugar muchas veces a impugnaciones o sospechas de ilegalidad que no son resueltas hasta momentos muy avanzados de la investigación judicial por el Tribunal Supremo o incluso por el Tribunal Constitucional, y además en ocasiones de forma contradictoria. Por tanto, resulta difícil ofrecer reglas o principios generales de actuación en torno a la toma de muestras de ADN que no puedan ser discutidos.

En principio, el sistema español parte de un modelo de toma de muestras basado en el consentimiento del afectado o, en su defecto, en la autorización judicial. La Disposición Adicional Tercera de la Ley Orgánica 10/2007 establece que "la toma de muestras que requieran inspecciones, reconocimientos o intervenciones corporales, sin consentimiento del afectado, requerirá en todo caso autorización judicial mediante auto motivado, de acuerdo con lo establecido en la Ley de Enjuiciamiento Criminal" (Ley Orgánica 10/2007, adicional tercera). Esta Disposición se remite por tanto, a su vez, al artículo 363 de la Ley de Enjuiciamiento Criminal, "el juez de instrucción podrá acordar, en resolución motivada, la obtención de muestras biológicas del sospechoso que resulten indispensables para la determinación de su perfil de ADN" (Ley de Enjuiciamiento Criminal, 1882, art. 363). Es decir, que cuando en una investigación criminal es necesaria la realización de un informe pericial de ADN, para la toma de las muestras biológicas se requerirá el consentimiento del afectado por tal diligencia, si bien, en caso de negativa, el juez podrá autorizar la toma.

Sin embargo, frente a este sistema "dual" la jurisprudencia viene reconociendo una tercera posibilidad respecto de los vestigios o las muestras abandonadas por el sospechoso. En estos casos, admite la posibilidad de su recogida por la Policía sin necesidad de recabar autorización judicial, lo que también ha quedado reflejado en la citada Disposición Adicional Tercera de la LO 10/2007: "para la investigación de los delitos enumerados en la letra a) del apartado 1 del artículo 3, la Policía Judicial procederá a la toma de muestras y fluidos del sospechoso, detenido o imputado, así como del lugar del delito" (Ley Orgánica 10/2007, Disposición adicional tercera) ${ }^{1}$.

En cuanto a la autorización judicial para la toma de muestras de ADN, en el referido artículo 326 de la Ley de Enjuiciamiento Criminal parece configurarse como una facultad que no requiere tomar en consideración previa el posible consentimiento del afectado: el juez lo puede acordar sin más. En cambio, la Disposición Adicional Tercera de la Ley Orgánica 10/2007 parece supeditar la autorización judicial a la previa negativa del sujeto afectado, lo que estimamos más razonable. Cuando una investigación criminal releve la necesidad de llevar a cabo una prueba de ADN que precise de la toma de muestras de un sospechoso/investigado, lo lógico es recabar previamente su consentimiento. Será en defecto de este consentimiento cuando proceda, en su caso, la autorización judicial para la toma de muestras. Y es que el análisis de ADN, como toda prueba criminal, no ha de ser visto como una diligencia necesariamente incriminatoria; puede constituir una prueba de descargo muy destacada para la defensa, y como tal ha de admitirse la posibilidad de que el propio afectado manifieste su deseo de colaborar con la justicia para su realización y poder demostrar así su inocencia. Siendo, en cualquier caso, una diligencia que afecta derechos fundamentales personalísimos, también parece razonable recabar el consentimiento previo del afectado, pudiendo así tomar conocimiento de que se pretende llevar a cabo, en lugar de decretar judicialmente su práctica

1 Como ilustrativa de esta triple posibilidad, podemos citar la STS 685/2010, 7 de julio. 
obligatoria de modo sorpresivo para el sospechoso sin darle opción siquiera de aceptar o rechazar su realización.

La resolución judicial ha de ser motivada. Ya que la prueba pericial de ADN es una diligencia que supone una evidente invasión en derechos fundamentales, solo podrá ser acordada cuando se considere absolutamente indispensable para la investigación judicial, y concurran los clásicos requisitos de necesidad, idoneidad y proporcionalidad.

La cuestión que debemos analizar detenidamente es qué sucede cuando el juez acuerda la toma de muestras, y pese a ello el investigado continúa negándose a facilitar una muestra biológica. Se trata de determinar, de una parte, cuáles son las consecuencias que se derivan de la negativa del sujeto a la toma de muestras biológicas para su análisis de $A D N, y$, de otra parte, si es posible recurrir al uso de la fuerza para la obtención coactiva de una muestra biológica.

\section{Análisis general de la negativa del sujeto a la toma de muestras. Consecuencias jurídicas}

La cuestión relativa al uso de la fuerza para la toma de muestras de ADN ha sido siempre una cuestión muy discutida. En principio, la jurisprudencia y la doctrina mayoritaria negaban la posibilidad de acudir a medios coactivos para la obtención de muestras biológicas.

Así, tanto la jurisprudencia del Tribunal Constitucional español (sentencias del Tribunal Constitucional (en adelante SSTC) 103/1985, 107/1985, 37/1989) como del Tribunal Supremo entendían que la resolución judicial habilitante no podía legitimar,

... la práctica de actos violentos o de compulsión personal, sometida a una reserva legal explícita -hoy por hoy, inexistente- que legitime la intervención, sin que pueda entenderse que la cláusula abierta prevista en el art. 549.1.c) de la LOPJ, colma la exigencia constitucional impuesta para el sacrificio de los derechos afectados. (Sentencia del Tribunal Supremo (en adelante STS) 685/2010, de 7 de julio)

Esta interpretación jurisprudencial se fundamentaba en la consideración de la intervención corporal como una "carga procesal", que como tal no podía imponerse mediante el recurso a la vis física al no establecerse una habilitación legal suficiente. La consecuencia de lo anterior es que esa negativa al sometimiento al análisis de $\mathrm{ADN}$, en tanto que carga procesal del sujeto, solo podía comportar una desventaja procesal en forma de "indicio de culpabilidad":

Como señala el Ministerio Fiscal tanto la jurisprudencia del Tribunal Europeo de Derechos Humanos (Sentencia 8 de Febrero de 1996, Caso Murray) y alguna referencia indirecta de la Sentencia del Tribunal Constitucional 7/1989 mantienen que, cuando la negativa a someterse a la prueba del ADN, carece de justificación o explicación suficiente, teniendo en cuenta que se trata de una prueba que no reporta ningún perjuicio físico y que tiene un efecto ambivalente, es decir puede ser inculpatorio o totalmente exculpatorio, nada impide valorar racional y lógicamente esta actitud procesal como un elemento que, por sí solo, no tiene virtualidad probatoria, pero que conectado con el resto de la prueba puede reforzar las conclusiones obtenidas por el órgano juzgador. (STS 107/2003, de 4 de febrero)

En esta misma línea, la doctrina mayoritaria defendía la imposibilidad de acudir a medios coactivos para la obtención de muestras genéticas. Si el investigado se negaba, ello únicamente podía valorarse como un indicio de su participación delictiva. Huertas Martín (1999) explica que:

Con ello se logra por un lado, la máxima protección de los derechos del imputado por la vía de impedir — como ocurriría en caso de que fuera obligación- que se vea convertido en un mero objeto y, por otro lado, la facilitación de la consecución de los fines del proceso penal, esto es, el castigo del culpable y la absolución del inocente. (p. 410)

Otros autores entendían que lo procedente era imputar al sujeto renuente un delito de desobediencia. Una vez que la autoridad judicial ha ordenado la medida, la negativa del sujeto debe entenderse como un incumplimiento de la orden judicial y debe castigarse como un delito de desobediencia ${ }^{2}$. Sin

2 Opción que ha tenido acogida en algunas resoluciones judiciales. A modo de ejemplo, puede citarse la SAP Madrid, Sección 2ạ , 67/2016, de 2 de febrero, que confirma una sentencia de condena por un delito de desobediencia con 
embargo, la STS 347/2010, de 20 de abril, parecía negar esta posibilidad, al confirmar la absolución dictada por la Sentencia de la Audiencia Provincial (en adelante SAP) Girona de fecha 4 de mayo de 2009 por un delito de desobediencia ante la negativa de un sujeto a someterse a la prueba de ADN: "en la fundamentación de la sentencia se motiva sobre la subsunción del hecho, declarando que tal hecho no es constitutivo del delito objeto de la acusación con remisión a la jurisprudencia de esta Sala y del Tribunal Constitucional" (SAP Girona, 2009) ${ }^{3}$.

los siguientes argumentos: "Este tribunal, ante las actuaciones remitidas, visionado del acto del juicio y sentencia dictada, entiende que el motivo invocado no puede prosperar, ya que concurren todos los elementos del tipo penal del art. 556 del Código Penal y ello porque el recurrente ha estado inmerso en el procedimiento seguido por delito de robo con violencia, uso de armas y delito de lesiones en el Juzgado de Instrucción no 3 de Madrid. Se le requirió para someterse a la extracción de muestras biológicas para el cotejo de ADN, mediante auto motivado que se le notificó personalmente y se le requería de las consecuencias negativas de oponerse y el acusado se ha negado, constando acreditada su negativa a someterse a la extracción. Se invoca el derecho a no declarar contra sí mismo y a no confesarse culpable y se debe señalar que en STS de 11/11/2014 'la toma de muestras de ADN no codificante no es un interrogatorio ni un reconocimiento de identidad. La toma de muestras de ADN solo constituye un elemento objetivo para la práctica de una prueba pericial, siendo una diligencia de investigación en cuya práctica está previsto el consentimiento informado del afectado y, en caso de negativa, la autorización judicial. No se puede afirmar que sea una diligencia netamente incriminatoria, extremo sobre el que hay unánime acuerdo jurisprudencial-STS 151/2010 de 22-2'. Es decir, que mediante autorización judicial se puede obtener tal diligencia de investigación y sin que ello afecte a su derecho a no declararse culpable. Por ello, el recurso no puede prosperar".

3 En aplicación de esta jurisprudencia, cabe citar la SAP Huelva, Sección 3a , 298/2013, de 17 de diciembre: "A la vista de la referida doctrina jurisprudencial consideramos, al igual que el juez a quo, que no es constitutiva de desobediencia esa falta de activa y voluntaria colaboración del acusado en la práctica de una prueba de ADN pues estimamos que no tiene obligación de prestar su colaboración activa en la práctica de pruebas que pueden incriminarle, al ostentar el derecho a negarse a colaborar en la práctica de tales pruebas al amparo de su derecho a no autoincriminarse. En consecuencia, los hechos enjuiciados no son constitutivos del delito de desobediencia y, por consiguiente, procede la desestimación del recurso".

En el mismo sentido, SAP Navarra, Sección 1ª, 132/2010, de 27 de julio: "Trasladada la expuesta argumentación y motivación al caso que es objeto de enjuiciamiento en el presente procedimiento, concretado en la negativa de los imputados a someterse a una prueba de ADN, ello nos conduce a alcanzar idéntica solución, con estimación del recurso de apelación y absolución de los imputados, siendo plenamente aplicable al hecho aquí enjuiciado aquella motivación y argumentación ya expuesta, no estimando que, en definitiva, pueda ser constitutiva de desobediencia esa falta de activa y voluntaria colaboración de los acusados en la práctica de una prueba de $A D N$ que, en definitiva, persigue la búsqueda de datos que pueden ser contundentemente incriminatorios,
No obstante la jurisprudencia, un sector minoritario de la doctrina defendía la posibilidad de acudir a medios coactivos. Matallín Evangelio (2008) entiende que no existe obstáculo constitucional para proceder a la ejecución coactiva de la muestra, mediante métodos mínimamente invasivos, siempre que se trate de una intervención corporal acordada en resolución judicial motivada, amparada en precepto adecuado y proporcionada a las circunstancias de caso. También González-Cuellar (1990):

Aunque el sujeto tiene derecho a no colaborar activamente en el éxito de la medida (en virtud de los derechos constitucionalmente reconocidos en los arts. 17.3 y 24.2 C.E., a no ser obligado a declarar — el detenido-, a no declarar contra sí mismo y a no confesarse culpable), sí se encontraría obligado a soportar las intervenciones pasivamente, por lo que si se resistiera los órganos de persecución podrían legítimamente proceder a la detención del individuo y a la aplicación de la fuerza para llevar a efecto la medida, impuesta como obligación procesal, siempre que la forma de ejecución de la injerencia no resultase desproporcionada, atendidas las circunstancias del caso. (pp. 294-295)

En realidad, lo cierto es que las objeciones jurisprudenciales y doctrinales al recurso a medios coactivos

y en relación con los cuales, conforme a lo anteriormente expuesto, estimamos que el acusado no tiene obligación de prestar su colaboración activa en la práctica de pruebas que pueden incriminarle. Avala tal conclusión la sentencia de fecha 20 de abril de 2010 dictada por el Tribunal Supremo en relación con un supuesto de negativa de un procesado al sometimiento a pruebas de ADN, en el que se absolvió al acusado del delito de desobediencia del artículo 556 del Código Penal que se le atribuía en relación a dicha negativa. Señaló el Tribunal Supremo en dicha sentencia, de un lado, que otorgar 'validez probatoria al silencio del acusado o a su negativa a colaborar en la indagación [...] supondría una vulneración del derecho a no confesarse culpable de los hechos y al principio nemo tenetur que permite al acusado en el enjuiciamiento no colaborar con la investigación en su perjuicio y no ser fuente de prueba si no es con su autorización'. De otro lado la citada sentencia, en relación con la fundamentación de la sentencia que era objeto del recurso de casación, sentencia de fecha 4 de mayo de 2009 dictada por la Sección Tercera de la Audiencia Provincial de Girona , en la que, como hemos dicho, se absolvió al procesado por el citado delito de desobediencia, señaló el Tribunal Supremo que 'en la fundamentación de la sentencia se motiva sobre la subsunción del hecho, declarando que tal hecho no es constitutivo del delito objeto de la acusación con remisión a la jurisprudencia de esta Sala y del Tribunal Constitucional', declarando no haber lugar a la casación de la citada sentencia recurrida que había absuelto, en el aspecto que aquí interesa, del delito de desobediencia atribuido al procesado". 
no se desarrollaban tanto en el plano constitucional o de garantías y derechos fundamentales, como en el plano de la ausencia de previsión legal al respecto. $\mathrm{Ni}$ la Ley de Enjuiciamiento Criminal ni la Ley Orgánica 10/2007 recogían expresamente la posibilidad de acudir al empleo de la fuerza para tomar la muestra biológica, por lo que se entendía que no había cobertura legal suficiente. Las objeciones jurisprudenciales al uso de la fuerza para la toma de muestras parecían referirse a la ausencia de norma legal habilitante, y no tanto a una posible inconstitucionalidad de la medida. Se sugería así la posibilidad de que el legislador, como ha terminado haciendo, pudiera legitimar determinados actos de compulsa física para proceder a la toma de muestras.

Una previsión legislativa que, ya lo adelantamos, no nos parece mal. Como vimos, nuestro sistema de perfiles de ADN se basa primordialmente en el doble juego del consentimiento o, en su defecto, la autorización judicial. Pero al no reconocer la posibilidad de acudir a su ejecución forzosa, la toma de muestras autorizada judicialmente terminaba siendo frustrada por la negativa del sujeto a la práctica de la diligencia. En cierto modo la autorización judicial no servía para nada, porque una vez acordada se volvía a recabar el consentimiento del sujeto y, si se negaba, la diligencia no se practicaba. La existencia de un indicio de culpabilidad era más teórica que real. Y la amenaza de un delito de desobediencia, ya de por sí difícil de justificar, tenía escasa fuerza al conllevar penas muy reducidas en comparación con las que sancionaban los delitos tan graves que habitualmente se investigan a través de la prueba de ADN. Al otorgarse cobertura a la ejecución coactiva de la muestra, la autorización judicial de la medida podrá tener plena eficacia.

Con ello también se evita la utilización de subterfugios legales para la obtención de muestras biológicas $^{4}$. Nos referimos principalmente a la llamada

4 Así lo resalta también Álvarez Buján (2018), partidaria de reconocer legislativamente el recurso a medios coactivos después de analizar las diversas opiniones doctrinales: “... al fin y a la postre, resulta más garantista tanto para los derechos del justiciable como para el interés social, acudir a la coerción física, ello claro está, siempre que se respete el principio de proporcionalidad y se lleve a efecto el pertinente juicio de idoneidad, necesidad y proporcionalidad en sentido estricto (aspectos que serán abordados al final de este capítulo). De esta forma se evita la utilización de subterfugios legales, como los que examinaremos a continuación, relativos fundamentalmente a la recogida de muestras y vestigios biológicos abandonados por la personas sospechosas o investigadas "toma subrepticia de la muestra" y a toda la problemática que plantea, como veremos a continuación.

\section{La obtención de muestras de ADN "por la puerta de atrás": la toma subrepticia de la muestra}

Sobre la posibilidad de que la Policía Judicial recogiera muestras biológicas sin consentimiento ni autorización judicial, la jurisprudencia se mostró vacilante hasta el Acuerdo del Tribunal Supremo de 31 de enero de 2006. Este Acuerdo no jurisdiccional se adopta tras dos sentencias con criterios contradictorios muy próximas en el tiempo: la STS 501/2005, de 19 de abril, que consideró nula la prueba obtenida por una toma de muestras abandonadas del sospechoso, y la STS de 1311/2005, de 14 de octubre, que no apreció vulneración alguna. El Acuerdo se inclina por la segunda postura y valida la actuación policial, estableciendo que "la Policía Judicial puede recoger restos genéticos o muestras biológicas abandonadas por el sospechoso sin necesidad de autorización judicial" (Acuerdo del Tribunal Supremo de 31 de enero de 2006). Este criterio se ha consolidado en las sentencias posteriores del Tribunal Supremo ${ }^{5}$.

De conformidad con Acón Ortego (2015a), hoy ya es criterio pacífico en la jurisprudencia que la Policía Judicial puede recoger muestras biológicas abandonadas por el sospechoso sin necesidad de autorización judicial. El fundamento normativo se encuentra en el artículo 282 de la Ley de Enjuiciamiento Criminal (1882), que faculta a la Policía Judicial para "recoger todos los efectos, instrumentos o pruebas del delito de cuya desaparición hubiere peligro, poniéndolos a disposición de la autoridad judicial". Y también en la citada Disposición Adicional Tercera de la LO 10/2007: "para la investigación de los delitos enumerados en la letra a) del apartado 1 del artículo 3, la Policía Judicial procederá a la toma de muestras y fluidos del sospechoso, detenido o imputado, así como del lugar del delito" (Ley Orgánica 10/2007, Disposición Adicional Tercera).

cuya pertinencia se les atribuye, pero en no pocas ocasiones sin una total certeza o garantía, pudiendo producirse contaminaciones y rupturas en la cadena de custodia que vengan a poner en entredicho el resultado final de los análisis genéticos".

5 SSTS 355/2006, de 20 de marzo; 949/2006, de 4 de octubre; 1267/2006, de 20 de diciembre; 1062/2007, de 27 de noviembre; 491/2013, de 31 de mayo, entre otras. 
Sucede que esta vía de la recogida de muestras no consentida ni autorizada, en la práctica ha dado lugar a operativas policiales muy discutibles, en las que a nuestro juicio se han flexibilizado, cuando no directamente vulnerado, las garantías que deben respetarse en toda prueba de ADN. No hay ningún problema en aceptar, con base en nuestra jurisprudencia y en la propia normativa, que la Policía Judicial puede recoger muestras biológicas del sospechoso cuando se trata de vestigios del delito. La ley claramente lo ampara, y además se trata de la forma lógica y razonable de proceder ante la presencia de cualquier vestigio, pues tener que solicitar autorización judicial retrasaría peligrosamente su recogida y podría impedir o dificultar su posterior análisis. El problema se plantea cuando la Policía no solo recoge el vestigio, sino que además lo analiza en un laboratorio policial e incluso introduce posteriormente el perfil genético obtenido en la base de datos de ADN sin recabar, en ninguna de estas fases de la operativa, la pertinente autorización judicial. Y también se producen dudas de legalidad y de constitucionalidad en aquellos otros casos en los que no se trata propiamente de un vestigio del delito, sino de una muestra abandonada por quien está siendo investigado como sospechoso del delito; muestra "atribuida" que la Policía recoge con la intención de analizarla, evitando así tener que pedir el consentimiento del afectado o, en su defecto, autorización judicial. Se trata de la llamada toma subrepticia de la muestra de ADN.

Lo cierto es que la jurisprudencia ha validado este tipo de operativas policiales discutidas ${ }^{6}$. Los argumentos empleados por el Tribunal Constitucional

6 La citada STS 1311/2005, de 14 de octubre, legitimó la actuación policial en un caso en el que la Ertzaintza recogió una muestra biológica de saliva de un esputo arrojado por el investigado al salir de la celda en la que se encontraba detenido, y procedió a su análisis para comparativa con los restos biológicos hallados en la prenda utilizada por el autor de los hechos y abandonada en su huida, todo ello sin autorización judicial ni por supuesto consentimiento del afectado. Frente a la resolución del Supremo se interpuso recurso de amparo, que dio lugar a la STC 199/2013, de 5 de diciembre. Como se ve en Acón Ortego (2015 a), pese a los —a nuestro juicio- sólidos argumentos del recurso, el Tribunal Constitucional desestimó el amparo, y consideró como prueba de cargo el análisis de una muestra de ADN tomada sin autorización judicial. Hubo tres votos particulares. En otras sentencias posteriores, el Tribunal Constitucional también ha desestimado recursos de amparo frente a este tipo de prácticas policiales sobre la prueba de ADN. Así, cabe citar las SSTC 13/2014, 14/2014, 15/2014 y 16/2014, todas ellas de 30 de enero de 2014, la STC 23/2014, de 13 de febrero, y la STC 43/2014, de 27 de marzo. son debatibles, como refiere Mardaras Aginako (2015), pero hay que admitir que termina por considerar que no son inconstitucionales prácticas policiales como las referidas. El Tribunal Constitucional admite que la Policía Judicial no solo puede recoger la muestra genética sin autorización judicial, sino que también puede analizarla para su comparativa con los vestigios del delito ${ }^{7}$.

Sin entrar a discutir los argumentos del Tribunal Constitucional, incluso dándolos por buenos, creemos que no es posible extraer conclusiones prácticas en cuanto a la forma de proceder en la práctica de ADN. Es decir, una cosa es que el Tribunal Constitucional no considere contrarias a la Constitución determinadas operativas policiales, porque en un caso concreto "concurran circunstancias excepcionales que permiten concluir que aun cuando el análisis de ADN efectuado no fuera ordenado judicialmente, no se lesionó el derecho del demandante a la intimidad personal" (STC 199/2013, de 5 de diciembre), y otra muy distinta es que de ello se derive una regla general o pauta de actuación que regule la forma de actuar de la Policía Judicial ante la existencia de vestigios biológicos; lo cual se puede observar en una investigación previa Acón Ortego, (2015a). Nos fundamentamos en las siguientes razones:

- El Tribunal Constitucional convalida una actuación irregular o, al menos, discutible jurídicamente, en atención a la gravedad de los hechos investigados

7 El Tribunal Constitucional razona del siguiente modo: “En cuanto a la necesidad de autorización judicial, recordábamos en la STC 70/2002, de 3 de abril, FJ 10, (y últimamente en la STC 115/2013, de 9 de mayo) que 'a diferencia de lo que ocurre con otras medidas restrictivas de derechos fundamentales que pueden ser adoptadas en el curso del proceso penal (como la entrada y registro en domicilio del art. 18.2 CE o la intervención de comunicaciones del art. 18.3 CE), respecto de las restricciones del derecho a la intimidad (art. 18.1 CE) no existe en la Constitución reserva absoluta de previa resolución judicial. No obstante, en la STC 37/1989, de 15 de febrero, en relación con la práctica de diligencias limitativas del ámbito constitucionalmente protegido del derecho a la intimidad, establecimos que era 'solo posible por decisión judicial' (FJ 7), aunque sin descartar la posibilidad de que en determinados casos y con la conveniente habilitación legislativa (que en tal caso no se daba), tales actuaciones pudieran ser dispuestas por la policía judicial (FJ 8)'. En particular, hemos admitido que la actuación policial pueda ser necesaria en atención a la urgencia de la actuación, el modo de comisión del delito o su gravedad (STC 173/2011, de 7 de noviembre). En el presente caso concurren circunstancias excepcionales que permiten concluir que aun cuando el análisis de ADN efectuado no fuera ordenado judicialmente, no se lesionó el derecho del demandante a la intimidad personal" (STC 199/2013, de 5 de diciembre). 
y demás circunstancias del caso. En el supuesto analizado por la STC 199/2013 se trata de un delito grave de terrorismo que, en caso de haber estimado el amparo, probablemente habría provocado la absolución del afectado. En cierto modo, con el juego del principio de proporcionalidad los intereses y fines de la investigación criminal se priorizan frente a los derechos del imputado. No parece que esta doctrina tenga la misma fuerza en las investigaciones de otros delitos menos graves en los que también puede recurrirse a la prueba de $A D N$, como robos o lesiones.

- La actuación que convalida el Tribunal Constitucional tiene importantes limitaciones y un sinfín de problemas prácticos: una muestra recogida por la Policía como "abandonada" es una muestra "atribuida", que por tanto no ofrece las mismas garantías que una muestra "indubitada"; no hay control judicial sobre la regularidad de toda la operativa; existen más argumentos para fundamentar una impugnación de la cadena de custodia; sin autorización judicial, no solo es discutible el análisis de la muestra, sino también la introducción del perfil obtenido en la base de datos; en definitiva, este tipo de actuaciones policiales van a estar sometidas desde el primer momento a una duda más que razonable sobre su validez. Lo normal es que se impugne en sede de instrucción y se mantengan las dudas durante todo el proceso, pudiendo llegar al Tribunal Supremo o al Tribunal Constitucional. Incluso una previsible impugnación podría llegar hasta el Tribunal Europeo de Derechos Humanos, cuya doctrina sobre la prueba de ADN es bastante garantista, como puede verse en la STEDH Marper vs. Reino Unido (2008). Siendo así, nos preguntamos: ¿le conviene a la Policía seguir esta operativa discutible, pese a las sentencias del Tribunal Constitucional, cuando fácilmente puede acudir a la autorización judicial para obtener y analizar la muestra genética? Especialmente en los casos de delitos graves de terrorismo, en los que la autorización judicial para el análisis comparativo de ADN parece garantizada.

- En este último sentido, cabría preguntarse si con la reforma del artículo 520.6 c) de la Ley de Enjuiciamiento Criminal no habría que replantearse la doctrina del Tribunal Constitucional. Con la habilitación legal del empleo de medios coactivos, la negativa del investigado ya no constituye obstáculo legal para practicar la prueba de ADN, ya que el juez puede acordar la obtención forzosa de la muestra. Siendo así, creemos que decaen definitivamente los argumentos del Tribunal Constitucional sobre la urgencia de la actuación policial, y que son todavía menores las razones de la Policía para tener que recurrir a una toma subrepticia de la muestra.

En la práctica así ha sucedido. La doctrina del Tribunal Constitucional solo ha servido para convalidar determinados supuestos muy excepcionales, y no para modificar las pautas de actuación policial. Los casos en los que la Policía Judicial ha acudido a tomas subrepticias de muestras de ADN o sin control judicial son muy escasos. Precisamente porque las sentencias del Tribunal Constitucional no han sido consideradas como legitimadoras de un protocolo general de actuación policial, la regla general es y sigue siendo que la Policía Judicial recabe el consentimiento informado del sospechoso para la toma de muestras biológicas y, en caso de negativa, la oportuna autorización judicial. Tratándose de vestigios o muestras abandonadas, la Policía Judicial puede recogerlas sin necesidad de autorización judicial, pero un buen actuar requiere recabar tal autorización o al menos la oportuna comunicación al juez para su control, cuando se pretenda llevar a cabo su análisis y la posterior inclusión del perfil obtenido en la base de datos de ADN. De lo contrario, se arriesga a que una sombra de sospechas de ilicitud recubra toda la investigación policial llevada a cabo.

La conclusión por tanto es clara. A pesar de la jurisprudencia del Tribunal Constitucional, conviene apostar por un reforzamiento de las garantías para evitar que todo el procedimiento de investigación policial y criminal se ponga en duda desde el primer momento, y que se vea amenazado hasta el final por una posible nulidad de la prueba incriminatoria. Los fines de la investigación policial no tienen que sufrir por ello merma alguna, todo lo contrario. Con la nueva habilitación legal que permite el empleo de medios coactivos para la obtención de muestras de $A D N$, puede asegurarse la práctica de la prueba de ADN sin tener que recurrir a esa "puerta de atrás" que supone la toma subrepticia de la muestra. 


\section{La ejecución coactiva de la toma de muestras}

\section{El artículo 520.6 c) de la Ley de Enjuiciamiento Criminal. Fundamento de la reforma}

La Ley Orgánica 13/2015, de 5 de octubre, de modificación de la Ley de Enjuiciamiento Criminal para el fortalecimiento de las garantías procesales y la regulación de las medidas de investigación tecnológica, introduce un nuevo artículo, 520.6 c), con el contenido antes referido.

6. La asistencia del abogado consistirá en:

... c) Informar al detenido de las consecuencias de la prestación o denegación de consentimiento a la práctica de diligencias que se le soliciten.

Si el detenido se opusiera a la recogida de las muestras mediante frotis bucal, conforme a las previsiones de la Ley Orgánica 10/2007, de 8 de octubre, reguladora de la base de datos policial sobre identificadores obtenidos a partir del ADN, el juez de instrucción, a instancia de la Policía Judicial o del Ministerio Fiscal, podrá imponer la ejecución forzosa de tal diligencia mediante el recurso a las medidas coactivas mínimas indispensables, que deberán ser proporcionadas a las circunstancias del caso y respetuosas con su dignidad. (Ley de Enjuiciamiento Criminal, 1882, artículo 520.6 c.)

La Exposición de Motivos de la reforma no contiene mención alguna a esta modificación. Pero podemos aseverar sin riesgo a equivocarnos que la intención del legislador fue la de tratar de asegurar la toma de muestras de ADN pese a la negativa del detenido. La Sala Segunda del Tribunal Supremo, reunida en Sala General en fecha 24 de septiembre de 2014, dictó un Acuerdo ${ }^{8}$ con el que puso fin a una discusión jurisprudencial que estaba resultando cada vez

8 Acuerdo del Tribunal Supremo de 24 de septiembre de 2014: "La toma biológica de muestras para la práctica de la prueba de ADN con el consentimiento del imputado precisa de la asistencia de letrado cuando el imputado se encuentra detenido o, en su defecto, de autorización judicial. Sin embargo, es válido el contraste de muestras obtenidas en la causa objeto de enjuiciamiento con los datos obrantes en la base de datos policial, procedentes de una causa distinta, aunque no conste la asistencia de letrado, cuando el acusado no ha cuestionado la licitud y validez de esos datos durante la fase de instrucción del proceso". más polémica, y se acogió el criterio que ya seguía la mayoría de los pronunciamientos del Tribunal Supremo ${ }^{9}$ en cuanto a la necesidad de presencia de un abogado para la toma consentida de muestras de ADN a un detenido.

Como se puede observar en una investigación anterior (Acón Ortego, 2014), lo que sucede con este Acuerdo del Tribunal Supremo es que para determinados sectores críticos, con el criterio adoptado se venía reclamando una solución legislativa urgente para evitar, según decían autores como Dolz Lago (2014), el previsible descenso de reseñas genéticas y asegurar la pervivencia de la base de datos policial de ADN. En esta línea, el Grupo Parlamentario Socialista propuso una enmienda al Proyecto de Ley de Estatuto de la Víctima en la que criticó "la deriva adoptada por la Sala Segunda" y propuso una modificación del artículo 363 de la Ley de Enjuiciamiento Criminal para validar la obtención de perfiles de ADN con el "consentimiento informado" del detenido, sin necesidad de asistencia letrada, cuando se realice mediante un frotis bucal. El anteproyecto de ley de reforma de la Ley de Enjuiciamiento Criminal se apuntó a las tesis de este sector crítico y recogió inicialmente una redacción del artículo muy distinta a la que terminó por aprobarse: "la asistencia letrada no será precisa para la recogida de muestras de sustancias biológicas del detenido con los fines previstos en la legislación sobre base de datos policiales sobre identificadores obtenidos a partir de ADN" (Anteproyecto de Ley de reforma de la Ley de Enjuiciamiento Criminal, 2014, art. 520). Esta previsión recibió enormes críticas y terminó por desaparecer del proyecto, precisamente por ir en contra de lo que ya era un criterio jurisprudencial consolidado y ofrecer serias dudas de constitucionalidad. En su lugar, al parecer con la misma finalidad de evitar un descenso significativo de reseñas genéticas por las posibles negativas asesoradas de letrado, lo que termina por recoger el precepto es la posibilidad de acudir a la ejecución forzosa de la toma de muestras mediante el recurso a las medidas coactivas mínimas indispensables, siempre que la autoridad judicial así lo permita.

9 Destacan las SSTS 940/2007, de 7 de noviembre; 685/2010, de 7 de julio; 353/2011, de 9 de mayo; y 827/2011, de 25 de octubre. 
Sin entrar en las reales motivaciones del legislador ${ }^{10}$, lo cierto es que la nueva previsión legislativa encuentra su justificación y puede tener perfecto acomodo en nuestra normativa sin entender vulneradas las garantías o exigencias constitucionales. Como dijimos, al no reconocer nuestro sistema la posibilidad de acudir a la ejecución forzosa de la toma de muestras, la autorización judicial para llevar a cabo el análisis de ADN terminaba siendo frustrada por la negativa del sujeto a la práctica de la diligencia. Ello daba cobijo a determinadas prácticas policiales de dudosa legalidad y constitucionalidad, que buscaban la obtención de muestras biológicas de modo subrepticio, sin contar con el consentimiento del sujeto ni autorización judicial.

No obstante lo anterior, es preciso tener en consideración que la prueba de ADN presenta diversos "escalones", y la toma de muestras tan solo es el primero de ellos. Como tiene declarado nuestra jurisprudencia en resoluciones como la STS 634/2010, de 28 de junio, la toma de muestras de ADN constituye una intervención corporal mínimamente invasiva que apenas requiere de la colaboración del sujeto afectado, sobre todo cuando se lleva a cabo mediante técnicas como el frotis bucal, lo cual permite que la autoridad judicial acuerde su ejecución coactiva legalmente prevista. Ahora bien, a nuestro juicio, en esa autorización el juez ha de tener en cuenta los restantes "escalones" de la prueba de ADN: la muestra se va a analizar, se va obtener un perfil de ADN, se va a comparar con las muestras biológicas halladas en el lugar del crimen investigado, e incluso se va a poder incorporar a la base de datos de ADN para su comparativa con vestigios de otros hechos delictivos. Es indudable que toda esta operativa afecta de un modo mucho más relevante los derechos fundamentales de defensa, intimidad y autodeterminación informativa. Nuestra insuficiente ley parece otorgarle importancia solo la habilitación del primer "escalón" (consentimiento o autorización judicial), y el resto de la operativa se desarrollaría de un modo automático. Pero precisamente por ello, al menos cuando es el juez quien resuelve sobre la autorización judicial para la toma de muestras, creemos que ha de tener presente no solo la posible (y mínima) injerencia corporal, sino toda la prueba de ADN que se desarrolla a continuación, operando

10 Es preocupante la banalización que muchas veces se produce de la prueba de ADN, bajo la errónea equiparación a la huella dactilar. Sobre esta cuestión, puede leerse a Guillén (2014) y Acón Ortego (2019). con los oportunos criterios de idoneidad, necesidad y proporcionalidad de la medida para salvaguardar los derechos y garantías en conflicto.

\section{Cuestiones problemáticas e interpretación jurisprudencial}

La redacción del artículo 520.6 c) párrafo segundo de la Ley de Enjuiciamiento Criminal no es demasiado afortunada para la finalidad que se le intuye. El precepto parece referido a una situación muy concreta: el detenido policial que, en presencia de su abogado, se niega a la práctica de la toma de muestras de ADN mediante frotis bucal. Pero los supuestos en los cuales puede concurrir la negativa a una muestra de ADN son más amplios, planteando dudas por ejemplo respecto a si es posible recurrir a una ejecución forzosa en el caso de sospechosos o investigados que no se encuentran detenidos. El artículo también parece limitar la toma de muestras a la técnica del "frotis bucal", siendo discutible que puedan utilizarse otros métodos de extracción. Surge incluso la duda de si esta nueva previsión solo es aplicable para llevar a cabo análisis genéticos comparativos con vestigios del delito (comparativa "uno contra uno"), o si además puede tener efectividad cuando de lo que se trata es de inscribir el perfil de ADN en la base de datos con fines de investigación criminal (comparativa "uno contra todos").

El análisis de las resoluciones judiciales en las que se ha aplicado este precepto nos permite extraer algunas conclusiones.

En primer lugar, cabe citar el Auto de la Audiencia (en adelante AAP) Barcelona 140/2017, de $1^{\circ}$ de marzo, en el que se legitima el uso de la fuerza "física" mínima imprescindible para tomar la muestra en un caso de agresión sexual. Parece claro que la nueva previsión permite los actos de compulsa "física", y no solo una coerción jurídica para "doblegar" la voluntad del afectado a la toma de muestras.

En el AAP León 850/2017, de 21 de julio, se legitima el uso de la fuerza para la toma de muestras a un sospechoso que no se encontraba detenido, es decir, que se hace uso del nuevo precepto entendiendo que la referencia al "detenido" no es limitadora de la posibilidad de acudir a una ejecución coactiva. En esta resolución se produce un análisis comparativo con restos de $\mathrm{ADN}$ hallados en un cadáver, en un caso de homicidio. Lo relevante de esta resolución es que la Audiencia Provincial de León 
cambia el criterio que había mantenido dos años antes, precisamente con fundamento en la nueva normativa. En el mismo sentido, puede mencionarse el AAP León 749/2017, de 23 de junio, en un caso de agresión sexual.

En los casos anteriores nos encontramos ante delitos de notoria gravedad, como homicidios ${ }^{11}$ o agresiones sexuales ${ }^{12}$. Pero también hay otras resoluciones judiciales en las que se autoriza la ejecución coactiva de la toma de muestras para delitos de menor entidad. Es el caso del AAP Pontevedra 164/2017, de 8 de marzo, en el que se autoriza la toma para su comparativa con restos de ADN en un caso de robo con violencia. También el AAP Córdoba 469/2017, de 19 de junio, en un caso de robo con fuerza, al igual que el APP Tarragona, Sección 2ª , 112/2018, de 21 de febrero ${ }^{13}$. Creemos que, en principio, sería posible la autorización judicial en todos aquellos casos en los que la ley permite la inscripción del perfil genético (delito grave $y$, en todo caso, los enumerados en el artículo 3.1 LO 10/2007), pero siempre bajo los parámetros de idoneidad, necesidad y proporcionalidad de la medida, con una mayor exigencia de motivación cuando se trata de delitos de menor gravedad.

Además, también habrá que tener en cuenta la finalidad pretendida con el análisis de ADN. El AAP Granada 298/17, de 10 de abril, sostiene que no es posible la ejecución coactiva de la muestra cuando la diligencia no va destinada a vincular a una persona determinada con un delito concreto (en este caso era un robo con fuerza), sino que la intención es la mera inclusión del perfil en la base de datos para investigar otros delitos que pueda haber cometido. En cambio, en el citado AAP Córdoba 469/2017, de 19 de junio, la finalidad de la toma

11 En otro caso de homicidio, como resolución judicial habilitante del empleo de medios coactivos, puede citarse el AAP Pontevedra, Sección 4a , 700/2017, de 25 de octubre.

12 También en caso de agresiones sexuales u otros delitos sexuales, pueden citarse las siguientes: AAP Girona, Sección 4a 472/2018, de 13 de agosto; AAP Girona, Sección 3ª , 602/2018, de 10 de octubre; AAP Barcelona, Sección 20åa, 129/2019, de 6 de febrero; o AAP Girona, Sección 3ạ , 163/2019, de 14 de marzo.

13 Esta última resolución razona lo siguiente: “En cuanto a la gravedad del delito, entendemos que el mismo encuentra encaje en los previstos en el art. 3 de la LO 10/2007 que recoge, en los términos antes indicados, los 'delitos graves $y$, en todo caso, los que afecten a [...] el patrimonio siempre que fuesen realizados con fuerza en las cosas, o violencia o intimidación en las personas [...]'". de muestras era únicamente la inclusión del perfil en la base de datos.

Entendemos que el artículo 520.6 c) se remite expresamente "a las previsiones de la Ley Orgánica 10/2007, de 8 de octubre, reguladora de la base de datos policial sobre identificadores obtenidos a partir del ADN" (Ley de Enjuiciamiento Criminal, 1882 , art. 520.6 c), de lo que se deduce que es perfectamente posible acordar la ejecución coactiva de la muestra para la incorporación del perfil en la base de datos, aunque en la causa judicial no sea necesario el análisis comparativo de ADN. Ahora bien, en tal caso el nivel de exigencia será mayor, debiendo tratarse de un delito especialmente grave que justifique hacer uso de la base de datos de ADN para la investigación de otros hechos delictivos que el sujeto pueda haber cometido (ej. homicidios, agresiones sexuales, abusos a menores de edad). En el caso de la citada resolución judicial de la Audiencia Provincial de Granada, probablemente es correcto entender que no concurre aquella justificación por tratarse de un delito de robo con fuerza. Por el contrario, no nos parece acertada la solución automática que propugna la Audiencia Provincial de Córdoba, siendo exigible una mayor motivación cuando de lo que se trata es de la inclusión del perfil obtenido en una causa judicial en la que se investiga un delito de menor gravedad, y además no es necesario el análisis comparativo con vestigio alguno.

La cuestión más problemática es qué se entiende por "medidas coactivas mínimas indispensables, que deberán ser proporcionadas a las circunstancias del caso y respetuosas con su dignidad" (Ley de Enjuiciamiento Criminal, 1882, artículo 520.6 c). Prácticamente todas las resoluciones judiciales citadas se limitan a recoger esta coletilla, dejando en manos de la Policía Judicial o del médico forense la forma de llevar a cabo la ejecución forzosa de la muestra. Tan solo vemos un mayor esfuerzo por concretar en el AAP Córdoba 469/2017, de 19 de junio, que valida el Auto del Juzgado de Primera Instancia e Instrucción de Aguilar de la Frontera en el que se establece lo siguiente:

SE ACUERDA: PRACTICAR EL EXAMEN de ADN de $x x x$, previa la extracción por parte del médico forense con la asistencia de la Secretaria Judicial de este Juzgado, bien de una muestra indubitada de sangre líquida o seca, o toma de células mucosas de la cavidad bucal, o pelos 
arrancados con bulbo, debiendo remitirse la citada muestra para el cotejo de su ADN con el existente en la muestra dubitada. Para llevar a efecto lo acordado, se delega y faculta a la unidad de Policía Judicial solicitante, la cual deberá informar urgentemente del resultado positivo o negativo de ello a este Juzgado. Si xxx negare su consentimiento a la práctica de la intervención corporal, PROCÉDASE por la Policía Judicial la obtención de muestras de cualquier tipo, usando todos los medios legales oportunos para la obtención de una muestra indubitada de cada uno de los imputados, como muestras hospitalarias conservadas, perfiles de ADN que estén recogidos en el historial clínico de los imputados y cualesquiera otros. (AAP Córdoba 469/2017, de 19 de junio)

Una previsión cuando menos llamativa, porque aparentemente con la finalidad de evitar una injerencia corporal (la toma de muestras de ADN mediante frotis bucal u otras técnicas) se faculta a la Policía Judicial para conseguir una muestra genética "de cualquier tipo", incluso mediante el acceso a información sanitaria, algo que en la práctica puede suponer una lesión al derecho a la intimidad del afectado mucho mayor que la se trata de evitar con la compulsa física.

Lo anterior revela las dificultades de llevar a cabo esa ejecución coactiva de la muestra "proporcionada" y "respetuosa con la dignidad" del afectado. En principio, las peculiaridades de la obtención de una toma de muestras de ADN permitirían ensayar soluciones mediante procedimientos mínimamente coactivos. Tratándose de una prueba que se practica sobre un resto biológico, su recogida podría obtenerse fácilmente sin el consentimiento del afectado pero también sin necesidad de acudir al uso de la fuerza física, pudiendo bastar con esperar el tiempo suficiente para que el investigado abandone una muestra biológica que le pueda ser atribuida durante la diligencia (ej. la caída de cabello, saliva en un vaso, la colilla de un cigarrillo). Se trataría de muestras "involuntarias", cuya obtención podría legitimarse expresamente en la autorización judicial al menos para advertir al afectado de que se trata de una diligencia ineludible, que no va a poder evitar de ningún modo con su negativa y falta de colaboración. Si a pesar de esta coerción jurídica el afectado mantiene su oposición a la diligencia, entonces ya no quedaría más remedio, si se quiere llevar a cabo, que adoptar medidas de compulsa física, las cuales serán en todo caso mínimas y necesarias para la finalidad pretendida. En este sentido, aunque la ley se refiere en todo momento al frotis bucal, creemos que este método es mínimamente invasivo cuando hay colaboración del sujeto, pero si se niega en rotundo puede suponer un método más violento que otros como la extracción forzosa de cabello. Por ello, no habría problema en que la ejecución forzosa se llevara a cabo a través de estos métodos alternativos o cualesquiera otros que se estimen menos invasivos, en atención a las circunstancias del caso concreto.

Por otra parte, entendemos que, una vez autorizada la toma de muestras por el juez, en su práctica no es precisa la asistencia letrada. El asesoramiento de un abogado es una garantía ineludible para que el detenido preste su consentimiento a la toma, pero no se exige que esté presente en la diligencia de extracción. La propia Comisión Nacional para el Uso Forense del ADN, como se recoge en su Memoria del año 2013, aclaró que había que distinguir el consentimiento para la toma de muestras de lo que es el momento mismo de la obtención: cuando el detenido ya ha consentido la toma de muestras con asistencia letrada, no es preciso que la posterior obtención de esas muestras por el personal correspondiente se haga, además, con la presencia de un letrado. Por la misma razón, una vez que existe habilitación para llevar a cabo la toma de muestras por la autoridad judicial, la diligencia puede llevarse a cabo (no será nula) sin la presencia obligatoria de un abogado $^{14}$. Esto sin perjuicio de que el letrado

14 En este sentido, puede citarse la SAP Barcelona, Sección $6^{\text {a }}$, 104/2019, de 12 de febrero: "Como resulta del juego combinado de los artículos 363 párrafo segundo, 520.6.c y 78 párrafo tercero de la Lecrim así como de la DA 3a de la LO 10/2007, de 8 de octubre, la asistencia letrada es la una [sic] precondición de la prestación del consentimiento para la extracción voluntaria de la muestra, pero no una condición de la regularidad de la diligencia de extracción en sí. En otros términos: la Lecrim no impone la asistencia del abogado defensor al concreto acto extractivo, pues nada añade, sino tan solo su asesoramiento previo para la emisión del consentimiento de la persona privada de libertad. Sin embargo, y con independencia del contenido del acta obrante al folio 65 , lo cierto es que el instructor, ante la negativa verbalizada en sede policial por el acusado, optó por dictar resolución motivada imponiendo la extracción. No se produjo, en consecuencia, la vulneración del derecho fundamental invocado, pues, aun cuando el letrado hubiera estado presente, poco podría haber manifestado al acusado más allá de advertirle que, de negarse, se habría procedido coactivamente, como señala el artículo 520.6.c Lecrim , en vigor en la fecha de los hechos [...] En consecuencia, pese a que en la práctica de la diligencia no se observaron dos de las prescripciones ordenadas por el instructor (presencia de 
pueda estar presente en la diligencia, lo que deberá admitirse sin problema si así lo solicita.

La ejecución coactiva de la recogida de muestras de ADN puede también encomendarse al médico forense ${ }^{15}$. Será lo procedente cuando la petición no provenga de la Policía Judicial, sino cuando lo solicite el Ministerio Fiscal o la necesidad de su práctica se ponga de manifiesto durante una investigación criminal, y también lo habitual cuando el juez encomiende el análisis pericial de ADN al Instituto Nacional de Toxicología y Ciencias Forenses, y no a un laboratorio policial. En aquellos casos en que el afectado se niegue a la toma de muestras, entendemos que la ejecución coactiva de la recogida también podrá llevarse a cabo por el médico forense si así se lo encomienda la autoridad judicial. Ahora bien, esto no significa que deba ser el médico forense el encargado de llevar a cabo los actos de compulsa física necesarios para la obtención de la muestra. Si no es posible obtener la colaboración activa del sujeto afectado, incluso pese a la coerción jurídica impuesta por la autoridad judicial, lo procedente será recabar el auxilio de la Policía Judicial para que el médico forense pueda cumplimentar la diligencia.

\section{La obtención coactiva de perfiles de ADN de condenados}

La reforma del Código Penal operada por la Ley Orgánica 1/2015, de 30 de marzo, también introdujo la posibilidad de inscribir perfiles genéticos de condenados por delitos graves en la base policial de datos de $\mathrm{ADN}^{16}$. Como se afirma en la Exposición

letrado y del letrado de la administración de justicia), ello no invalida, per se, la diligencia cuando no existe afectación del derecho fundamental invocado (derecho a la asistencia letrada)".

15 El artículo 326 de la Ley de Enjuiciamiento Criminal así lo permite expresamente. De este precepto se deriva no solo la posibilidad de que el juez encomiende al médico forense la diligencia, sino también sus plenas atribuciones para "garantizar la autenticidad" de la muestra genética recogida. Dicha actuación no requiere de la intervención de un letrado de la administración de justicia, la ley no lo contempla y por tanto no es preceptiva. Ello sin perjuicio de que en determinadas ocasiones se pueda considerar conveniente o adecuado que en la toma de muestras también esté presente un letrado de la administración de justicia, pero su ausencia en ningún caso invalida la toma.

16 Artículo 129 bis del Código Penal: "Si se trata de condenados por la comisión de un delito grave contra la vida, la integridad de las personas, la libertad, la libertad o indemnidad sexual, de terrorismo, o cualquier otro delito grave que conlleve un riesgo grave para la vida, la salud o la integridad física de las de Motivos de la reforma, se pretende dar cobertura a las exigencias del Convenio del Consejo de Europa para la protección de los niños contra la explotación y el abuso sexual, hecho en Lanzarote el 25 de octubre de 2007, ratificado por España el 22 de julio de $2010^{17}$.

La Ley Orgánica 10/2007, de 8 de octubre, reguladora de la base de datos policial sobre identificadores obtenidos a partir del ADN, tan solo contemplaba la inscripción de perfiles de sospechosos, detenidos o imputados por la comisión de delitos graves (artículo 3). Esto permitía cumplir en cierta medida con las exigencias del Convenio de Lanzarote, porque la condena por delitos de explotación y abuso sexual da lugar al mantenimiento del perfil genético que ya se hubiera registrado en la base de datos. Sin embargo, este sistema no siempre garantizaba que todos los condenados por delitos relativos a la explotación y el abuso sexual quedaran registrados en la base de datos de ADN, ya que en ocasiones su perfil como sospechoso o imputado no se registraba. Era frecuente que existieran suficientes indicios de criminalidad para acreditar la participación en el hecho delictivo sin necesidad de recurrir a pruebas genéticas, y en la práctica esto daba lugar a que no se procediera a la toma de muestras de ADN de sospechosos o imputados, incluso por aquellos delitos que el Convenio de Lanzarote obliga a inscribir en las bases de datos. De ahí la necesidad de la reforma del año $2015^{18}$.

personas, cuando de las circunstancias del hecho, antecedentes, valoración de su personalidad, o de otra información disponible pueda valorarse que existe un peligro relevante de reiteración delictiva, el juez o tribunal podrá acordar la toma de muestras biológicas de su persona y la realización de análisis para la obtención de identificadores de ADN e inscripción de los mismos en la base de datos policial. Únicamente podrán llevarse a cabo los análisis necesarios para obtener los identificadores que proporcionen, exclusivamente, información genética reveladora de la identidad de la persona y de su sexo. Si el afectado se opusiera a la recogida de las muestras, podrá imponerse su ejecución forzosa mediante el recurso a las medidas coactivas mínimas indispensables para su ejecución, que deberán ser en todo caso proporcionadas a las circunstancias del caso y respetuosas con su dignidad".

17 BOE-A-2010-17392, 12 de noviembre de 2010.

18 No obstante, la reforma no se justifica únicamente por la necesidad de cumplir el Convenio del Consejo de Europa. En general se venía reclamando la ampliación de nuestro sistema de base de datos de ADN hacia un modelo de inscripción de perfiles genéticos de condenados, y no solo de sospechosos/ imputados. En el ámbito de la propia CNUFADN, se había puesto de manifiesto la necesidad de esta reforma legislativa para aproximarnos a otros países de nuestro entorno europeo que ya incorporaban desde hace tiempo perfiles de condenados en sus bases de datos, y solventar algunos 
La nueva previsión no va a acompañada de una modificación de la Ley Orgánica 10/2007, de 8 de octubre, como habría sido deseable, y plantea innumerables problemas prácticos en cuanto a la forma de proceder para la recogida e inscripción del ADN de los condenados, así como para su cancelación ${ }^{19}$. Habrá de entenderse que la reforma amplía el ámbito de aplicación de esa ley reguladora de la base policial de datos de ADN, y será preciso adaptar sus previsiones a la posibilidad de incluir perfiles de condenados.

En lo que aquí nos interesa, el artículo 129 bis prevé las consecuencias de la negativa del condenado a someterse a las pruebas de ADN: "podrá imponerse su ejecución forzosa mediante el recurso a las medidas coactivas mínimas indispensables para su ejecución, que deberán ser en todo caso proporcionadas a las circunstancias del caso y respetuosas con su dignidad" (Código Penal, 1995, art. 129 bis).

Hay que tener en cuenta que esta previsión es anterior al nuevo artículo 520.6 c) párrafo segundo de la Ley de Enjuiciamiento Criminal. Se introdujo con la reforma del Código Penal que entró en vigor en septiembre de 2015 y constituye antecedente de la posterior reforma de la Ley de Enjuiciamiento Criminal en octubre de ese mismo año. Es probable que el legislador ya tuviera en mente regular el uso de la fuerza en sede de investigación, y lo anticipara también para los casos de perfiles de ADN de condenados. Pero lo cierto es que en este caso la previsión resulta un tanto distorsionadora. Como hemos mencionado, la inscripción del perfil de ADN de un condenado no precisa de su consentimiento, sino que se impone como consecuencia accesoria a la pena. La redacción del artículo 129 bis parece presuponer un consentimiento del sujeto que no es necesario. Salvando las distancias, es tanto como regular las consecuencias de la negativa del condenado a ingresar en prisión, cuando se le condene a ello; es claro que el condenado no puede negarse y, de hacerlo, se impondrá su ejecución coactiva. La legitimación expresa del uso de la fuerza tiene más sentido en el ámbito de las medidas policiales/ judiciales de investigación, en sede de instrucción, pero no tanto en ejecución de una sentencia de

problemas que dificultaban el desarrollo de nuestro sistema de almacenamiento de perfiles de ADN.

19 Cuestión de singular importancia, por las exigencias del Tribunal Europeo de Derechos Humanos (de nuevo STEDH Marper vs. Reino Unido 2008). condena. Son planos diferentes: en el ámbito de la investigación penal, una regulación legal del uso de la fuerza para llevar a cabo intervenciones corporales resulta discutible pero entendible; en sede de ejecución de penas, probablemente resulta innecesaria.

En cualquier caso, vale lo dicho en cuanto a la ejecución coactiva de la toma de muestras en sede de instrucción, a lo que nos remitimos. La única peculiaridad es que se producirá en sede de ejecución de sentencia por parte del tribunal sentenciador, y lo normal es que se recurra a la actuación del médico forense para la toma de muestras y a su posterior remisión al Instituto Nacional de Toxicología y Ciencias Forenses para la incorporación del perfil de ADN.

\section{CONCLUSIONES}

De todo lo anterior, extraemos las siguientes conclusiones prácticas:

- Tras la reforma operada por la Ley Orgánica 13/2015, de 5 de octubre, el sistema español admite la ejecución forzosa de la toma de muestras genéticas para el análisis del ADN en investigación criminal.

- En principio, se trata de una medida contemplada en la ley que no ofrece dudas de constitucionalidad, si bien el juez la acordará cuando la estime indispensable para la investigación criminal y concurran los requisitos de idoneidad, necesidad y proporcionalidad de toda medida invasiva en derechos fundamentales, debiendo valorar los derechos y garantías en conflicto de toda prueba de ADN.

- Con esta nueva previsión normativa, ha de revisarse la doctrina constitucional que amparaba la llamada "toma subrepticia" de la muestra de ADN, pues la negativa del investigado ya no constituye obstáculo legal para practicar la prueba de ADN.

- Aunque el nuevo precepto se refiere únicamente al "detenido", parece posible la ejecución forzosa de la toma de muestras en supuestos en los cuales el sospechoso o investigado no se encuentra detenido. Carece de sentido que la ley limite esta posibilidad a detenidos policiales (artículo 520.6c Lecrim) y a condenados (artículo 129 bis Código Penal), y se prohíba para los investigados 
en causas judiciales no detenidos; cuando está mucho más justificada la necesidad de la diligencia, concurren mayores indicios de criminalidad, y el juez dispone de más elementos para decretar su práctica. De no entenderlo así, podría existir la tentación de recurrir a la detención para poder llevar a cabo la toma de las muestras, lo que supondría una lesión en derechos fundamentales añadida y absolutamente innecesaria.

- La ejecución forzosa no solo es posible para realizar un análisis comparativo de ADN con restos biológicos; también será posible para la mera inclusión en la base de datos de ADN con el fin de investigar otros delitos que el sujeto puede haber cometido, si bien en este caso el nivel de exigencia en la motivación judicial ha de ser mayor.

- Conforme el artículo 520.6c Lecrim, la solicitud para la autorización judicial puede proceder "de la Policía Judicial o del Ministerio Fiscal". Cuando la solicitud proceda de la Policía, lo normal es que la autoridad judicial encomiende a esta la práctica de la diligencia y le faculte para llevar a cabo los actos coactivos mínimos indispensables; cuando la petición proceda del Ministerio Fiscal en el curso de una investigación judicial, la práctica de la diligencia también podrá encomendarse al médico forense. Entendemos que también sería posible constatar la necesidad de un análisis de ADN de oficio por el juez o a petición de una acusación particular, en cuyo supuesto lo razonable es dar traslado al Ministerio Fiscal para que habilite, en su caso, la posibilidad de recurrir al artículo 520.6c Lecrim. Igualmente, sería conveniente dar traslado previo a la defensa para que manifieste si consiente la diligencia o para que formule las alegaciones que a su derecho convenga.
- Entendemos que, una vez autorizada la toma por el juez, en su práctica no es precisa la asistencia letrada. El asesoramiento de un abogado es una garantía ineludible para que el detenido preste su consentimiento a la toma, pero no se exige que esté presente en la diligencia de extracción. Por la misma razón, una vez que existe habilitación para llevar a cabo la toma de muestras por la autoridad judicial, la diligencia puede llevarse a cabo (no será nula) sin la presencia obligatoria de un abogado. Esto sin perjuicio de que el letrado pueda estar presente en la diligencia, lo que deberá admitirse sin problema si así lo solicita.

- En cuanto a las medidas coactivas mínimas indispensables, tratándose de una prueba que se practica sobre restos biológicos podrían ensayarse soluciones que permitan la recogida de muestras "involuntarias", esto es, abandonadas por el afectado durante la propia diligencia (ej. la caída de cabello, saliva en un vaso, la colilla de un cigarrillo). Pero en caso de oposición rotunda del afectado y falta de colaboración, deberá recurrirse a los actos de compulsa física mínimos que sean necesarios para recoger la muestra, pudiendo utilizarse métodos como la extracción de cabello u otros procedimientos mínimamente invasivos, y no necesariamente acudir al frotis bucal que en la práctica puede ser más violento que otros métodos posibles.

- Las mismas conclusiones son aplicables a la obtención coactiva de perfiles de condenados. La única peculiaridad es que se producirá en sede de ejecución de sentencia por parte del Tribunal sentenciador, y lo normal es que se recurra a la actuación del Médico Forense para la toma de muestras y a su posterior remisión al Instituto Nacional de Toxicología y Ciencias Forenses para la incorporación del perfil de ADN. 


\section{REFERENCIAS}

Acón Ortego, I. (2014). La toma de muestras de ADN y la pervivencia de la base de datos. El Derecho, Tribuna Penal, 3 de diciembre de 2014. Recuperado de https://elderecho.com/ la-toma-de-muestras-de-adn-y-la-pervivencia-de-la-base-de-datos

Acón Ortego, I. (2015a). La inscripción de perfiles de ADN de condenados. El Derecho, Tribuna Penal, 19 de mayo de 2015. Recuperado de https://elderecho.com/la-inscripcion-deperfiles-de-adn-de-condenados

Acón Ortego, I. (2019). Aspectos jurídicos y bioéticos del uso forense del ADN. En Crespillo Márquez, M.C. y Barrio Caballero, P. A. (Coords.): Genética forense: del laboratorio a los tribunales. Ediciones Díaz de Santos.

Álvarez Buján, M. (2018). Análisis crítico sobre la prueba de $A D N$ : virtualidad científica y jurídica. [Tesis de doctorado]. Universidad de Vigo. Escola Internacional de Doutoramento.

Casado, M. y Guillén, M. (2014). ADN forense: problemas éticos y jurídicos. Barcelona: Edicions de la Universitat de Barcelona.

Código Penal [CP], Ley Orgánica 10/1995, de 23 de noviembre, del Código Penal. Artículo 129 bis. BOE núm. 281, de 24 de noviembre de 1995.

Crespillo Márquez, M.C. y Barrio Caballero, P. A. (Coords.) (2019): Genética forense: del laboratorio a los tribunales. Ediciones Díaz de Santos.

Dolz Lago, M. J. (2014). Pruebas de ADN en el proceso penal: crónica de una muerte anunciada gracias a la jurisprudencia de la sala $2^{\underline{a}}$ del TS que desconoce lo que es el ADN no codificante. Diario La Ley, 8284, 1.
González-Cuéllar, N. (1990). Proporcionalidad y derechos fundamentales en el proceso penal. Editorial Colex.

Guillén, M. (2019). La mal Ilamada huella genética. Una metáfora científica frente al uso forense de la prueba de ADN. En M. Casado y M. Guillén (Eds.). ADN forense: Problemas éticos y jurídicos. Edicions de la Universitat de Barcelona.

Huertas Martín, M. I. (1999). El sujeto pasivo del proceso penal como objeto de la prueba. Librería Bosch.

Instrumento de Ratificación del Convenio del Consejo de Europa para la protección de los niños contra la explotación y el abuso sexual, hecho en Lanzarote el 25 de octubre de 2007. BOE núm. 274, de 12 de noviembre de 2010, . 94858 a 94879. Referencia: BOEA-2010-17392. Recuperado de https://www. boe.es/eli/es/ai/2007/10/25/(1)

Ley de Enjuiciamiento Criminal [Lecrim]. Real Decreto de 14 de septiembre de 1882 por el que se aprueba la Ley de Enjuiciamiento Criminal, artículos 282, 326, 336, 520. BOE núm. 260, de 17 de septiembre de 1882 .

Ley Orgánica 13/2015, de 5 de octubre, de modificación de la Ley de Enjuiciamiento Criminal para el fortalecimiento de las garantías procesales y la regulación de las medidas de investigación tecnológica. BOE núm. 239, de 6 de octubre de 2015, pp. 90192 a 90219.

Mardaras Aginako, A. (2015). La toma subrepticia de muestras de ADN por la policía: comentario de la STC 199/2013, de 5 de diciembre/Sureptitious DNA sampling by police. Revista Española De Derecho Constitucional, 105, 285-313.

Matallín Evangelio, Á. (2008). Intervenciones corporales ilícitas: Tutelas penales. Tirant lo Blanch. 


\section{Bibliografía consultada}

Alonso Alonso, A. (2004). Conceptos básicos de ADN forense. Estudios Jurídicos.

Alonso Alonso, A. (2004). Las bases de datos de ADN en el ámbito forense. Estudios Jurídicos.

Alonso Alonso, A. (2012). Las bases de datos de ADN forense en España y la labor desarrollada por la comisión nacional para el uso forense del ADN. Estudios Jurídicos.

Álvarez de Neyra Kappler, S. (2004). Valoración e interpretación de la prueba pericial sobre ADN ante los tribunales. Estudios Jurídicos.

Álvarez de Neyra Kappler, S. (2008). La prueba de ADN en el proceso penal. Granada: Editorial Comares.

Álvarez de Neyra Kappler, S. (2013). El consentimiento informado en la toma de muestras genéticas a detenidos y la asistencia letrada (1): La coactividad en la toma de muestras. La Ley Penal: Revista De Derecho Penal, Procesal y Penitenciario, 102, 1 y ss.

Álvarez de Neyra Kappler, S. (2017). La protección del derecho a la intimidad en la toma de muestras de ADN a fines de investigación penal. lus Et Scientia, 3(1), 48-62.

Cabezudo Bajo, M. J. (2012). La regulación del "uso forense de la tecnología del ADN" en España y en la UE: identificación de cinco nuevas cuestiones controvertidas. Revista General De Derecho Procesal, 26, 6 y ss.

Carracedo, A. (2013). ADN: La genética forense y sus aplicaciones en investigación criminal. Santiago de Compostela: Instituto Deficiencias Forenses, Universidad de Santiago de Compostela.

Carracedo, A., Salas, A. y Lareu, M. (2010). Problemas y retos de futuro de la genética forense en el siglo XXI. Cuadernos De Medicina Forense, 16(1-2), 31-35.

Cuenca, P. L. y Calvo, M. (2016). Recogida de ADN en el nuevo CP: Consecuencias jurídicas y éticas del artículo 129 bis CP. Diario La Ley, 8738, 2.

Del Olmo, J. A. (2012). Las garantías procesales en la identificación de imputados mediante perfiles de ADN. La Ley Penal, 91, 20-47.

Dolz Lago, M. J. (2012). ADN y derechos fundamentales: Breves notas sobre la problemática de la toma de muestras de ADN - frotis bucal - a detenidos e imputados. Diario La Ley, 7774, 1.

Gudín Rodríguez-Magariños, A. (2015). El empleo de la vis física para la toma de muestras de ADN. Diario La Ley, 8571, 2.

Magro Servet, V. (2012). Las intervenciones corporales por los agentes de la autoridad: ¿̇ntervención judicial permanente y en cualquier caso? La Ley Penal: Revista de Derecho Penal, Procesal y Penitenciario, 89, 5.

Marca Matute, J. (2016). ADN y las últimas reformas procesales y penales. Ponencia presentada en el Curso de Formación Continua del CGPJ La prueba del ADN en la investigación criminal y en la identificación de desaparecidos. Escuela Judicial CGPJ Madrid, 2-4 de noviembre de 2016.

Pastor, J. M. (2012). La recogida por la policía judicial de muestras biológicas para la práctica de la prueba pericial de ADN en el proceso penal y el régimen de sometimiento del sujeto pasivo de las medidas de inspección, registro o intervención corporal. La Ley Penal: Revista De Derecho Penal, Procesal y Penitenciario, 89, 3. 